\title{
Alkoxy-directed cyclopropanation of 1,1-disubstituted alkenes with esters: New approach to quaternary carbon centers $\dagger$
}

\author{
Nagavaram Narsimha Rao and Jin Kun Cha* \\ Department of Chemistry, Wayne State University, 5101 Cass Ave, Detroit, MI 48202, U.S. A. \\ Phone: (313) 577-1073; Fax: (313) 577-8822; Email: jcha@chem.wayne.edu
}

\section{ARTICLE INFO ABSTRACT}

Article history:

Received

Received in revised form

Accepted

Available online

\section{Keywords:}

Cyclopropanation

Cyclopropanol

Homoenol

Directing group

Quaternary Center
As a new approach to the stereocontrolled construction of quaternary centers, 1,2,2-trisubstituted cyclopropanols are prepared by the olefin exchange-mediated Kulinkovich cyclopropanation of esters with 1,1-disubstituted alkenes bearing homoallylic alcohols. Central to the successful cyclopropanation is the generation of a temporary alkoxy tether from a homoallylic alcohol.

2009 Elsevier Ltd. All rights reserved.

Subsequent to a remarkable cyclopropanation reaction of carboxylic esters discovered by the Kulinkovich group, 1 we developed the olefin exchange-mediated variant to broaden the scope of the Kulinkovich cyclopropanation of carboxylic acid derivatives.2,3 The olefin exchange-mediated cyclopropanation of esters relies on cyclohexyl or cyclopentyl Grignard reagents to generate the requisite titanacyclopropane (Kulinkovich) intermediates and is limited to the use of monosubstituted olefins to afford cis-1,2-dialkyl substituted cyclopropanols.2 A temporary linker tactic of utilizing homoallylic alcohols was recently utilized for the preparation of the otherwise inaccessible more substituted cyclopropanols (Scheme 1): a temporary alkoxide tether overrides the intrinsic steric bias (toward the monosubstituted titanacyclopropanes over the disubstituted ones), which is implicit in the olefin exchange-mediated cyclopropanation.4 This temporary tether strategy has also been effective for stereoselective cyclopropanation of homoallylic alcohols,5,6 olefin exchange-mediated cyclopropanation of nitriles, 7 and cross-coupling reactions between two unsaturated components.8,9 We report herein the Kulinkovich cyclopropanation of 1,1-disubstituted alkenes bearing homoallylic alcohols for the convenient preparation of 1,2,2trisubstituted cyclopropanols. Also included are ring-opening reactions of the latter products for the stereocontrolled construction of all-carbon quaternary centers. 


\section{Scheme 1}
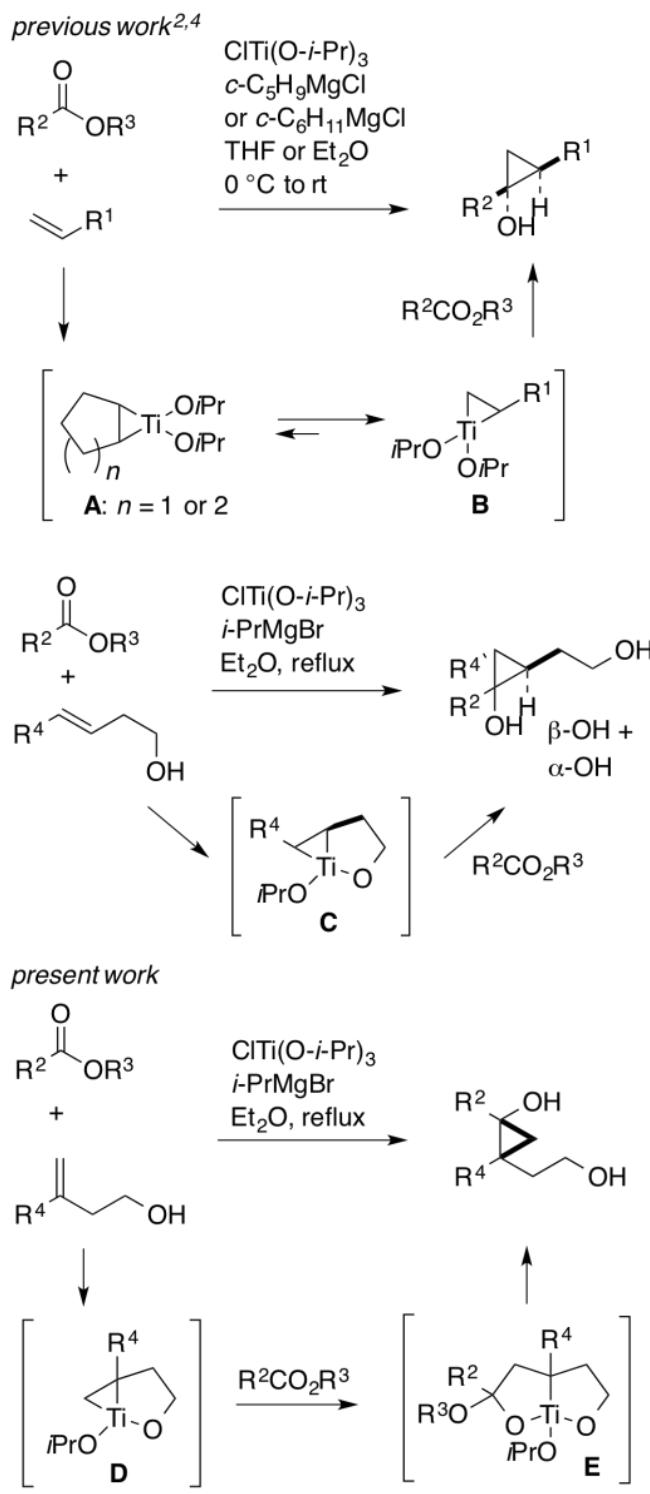

The olefin exchange-mediated cyclopropanation reaction of esters is predicated on steric effects to drive the key equilibrium from the less stable, disubstituted titanacyclopropane (Kulinkovich) intermediate $\mathbf{A}$ to the more stable, requisite intermediate B (Scheme 1). ${ }^{2}$ Consequently, substrate scope was limited to monosubstituted alkenes. The use of an in situ generated tether (e.g., C) between a homoallylic alcohol and a Kulinkovich intermediate as a directing group was successfully exploited to countermand the central steric bias to effectuate the otherwise unfavorable olefin exchange: the preparation of 1,2,3trialkyl substituted cyclopropanols was indeed made possible from 1,2-disubstituted alkenes equipped with a homoallylic alcohol moiety. ${ }^{4}$ To expand substrate scope, we next examined the cyclopropanation reaction of 1,1-disubstituted alkenes by utilizing the identical directing group (i.e., homoallylic alcohol) strategy.

The commercially available 3-methyl-3-buten-1-ol (1) was chosen as a prototype of 1,1-disubstituted alkenes bearing homoallylic alcohols (Table 1). When the cyclopropanation reaction of $\mathbf{1}$ with ethyl acetate (2a) was carried out under reaction conditions $\left[\mathrm{ClTi}(\mathrm{O}-i-\mathrm{Pr})_{3}\right.$ and $i-\mathrm{PrMgBr}$ in $\mathrm{Et}_{2} \mathrm{O}$ at reflux] previously optimized for 1,2-disubstituted counterparts, ${ }^{4}$ the desired cyclopropanol 3a was obtained as a single isomer in $67 \%$ yield (entry 1). According to a brief survey of solvents and reaction temperature an $\mathrm{Et}_{2} \mathrm{O}$ solution at reflux (entries 1-4) appeared to be optimal. When judged by TLC, the reaction proceeded cleanly but modest yields were attributed to the presence of unreacted 1 (in 10-23\% yield). Larger amounts of $\mathbf{1}$ were recovered at $\mathrm{rt}$ as a consequence of the inherently low reactivity of disubstituted alkenes. The isolated yields were given in Table 1, and the adjusted yields based on the recovered alkenes were satisfactory. The cyclopropanol by-product derived from the isopropyl Grignard reagent (i.e., the original Kulinkovich reaction product) was present in small amounts, but not isolated due to its volatility. A reaction mechanism is likely to involve the intermediacy of $\mathbf{D}$ and $\mathbf{E}$ (Scheme 1), followed by subsequent ring closure via the corresponding titanium homoenolate (not shown) and the seven-membered cyclic titanate.

Cyclopropanation of $\mathbf{1}$ with other esters was next carried out under identical conditions (entries 5-8), and the corresponding cyclopropanols 3a-e were obtained in comparable yields. ${ }^{10,11}$ The stereochemical determination of $\mathbf{3 a}-\mathbf{e}$ was secured by facile formation of the seven-membered cyclic acetals with acetaldehyde.

Table 1.

\begin{tabular}{|c|c|c|c|c|c|c|}
\hline $\begin{array}{l}\mathrm{R}^{2} \mathrm{C} \\
(2 \\
2\end{array}$ & $\begin{array}{l}\quad 1 \\
+\quad 1 \\
\mathrm{CO}_{2} \mathrm{R}^{3} \\
\text { equiv) } \\
\text { a-e }\end{array}$ & & $\begin{array}{l}\mathrm{Ti}(\mathrm{O} \mathrm{P} \\
\mathrm{MgBr} \\
6-8 \mathrm{e} \\
\text { vent, }\end{array}$ & & $\begin{array}{l}3 \mathbf{a}-\mathbf{} \\
1: 0\end{array}$ & \\
\hline entry & $2 / 3 a-e$ & $\mathrm{R}^{2}$ & $\mathrm{R}^{3}$ & solvent & $\mathrm{T}\left({ }^{\circ} \mathrm{C}\right)$ & yield (\%) \\
\hline 1 & $\mathbf{a}$ & $\mathrm{Me}$ & $\mathrm{Et}$ & $\mathrm{Et}_{2} \mathrm{O}$ & 35 & 67 \\
\hline 2 & a & $\mathrm{Me}$ & Et & $\mathrm{Et}_{2} \mathrm{O}$ & 20 & 58 \\
\hline 3 & $\mathbf{a}$ & $\mathrm{Me}$ & $\mathrm{Et}$ & THF & 66 & 42 \\
\hline 4 & a & $\mathrm{Me}$ & Et & THF & 20 & 22 \\
\hline 5 & b & $n \mathrm{C}_{7} \mathrm{H}_{15}$ & $\mathrm{Me}$ & $\mathrm{Et}_{2} \mathrm{O}$ & 35 & 57 \\
\hline 6 & c & $i \mathrm{C}_{4} \mathrm{H}_{9}$ & Et & $\mathrm{Et}_{2} \mathrm{O}$ & 35 & 65 \\
\hline 7 & d & $i \mathrm{C}_{3} \mathrm{H}_{7}$ & Et & $\mathrm{Et}_{2} \mathrm{O}$ & 35 & 61 \\
\hline 8 & e & $c \mathrm{C}_{6} \mathrm{H}_{11}$ & Et & $\mathrm{Et}_{2} \mathrm{O}$ & 35 & 54 \\
\hline
\end{tabular}

Overall, the alkoxide-directed cyclopropanation of $\mathbf{1}$ parallels that of 1,2-disubstituted counterparts. Two noticeable differences between two alkene substrates are: 1. outstanding (1:0) diastereoselectivity for 1,1-disubstituted alkenes; 2 . little disparity in yields among different esters. In comparison, the corresponding cyclopropanation reaction of 1,2-disubstituted reactants was sensitive to steric effects, so that $\alpha$-branched esters suffered in both yield and diastereoselectivity, presumably due to greater nonbonded interactions present in the final ring closing step. 4

Cyclopropanation of other 1,1-disubstituted alkenes with ethyl acetate was also investigated under identical conditions (Scheme 2). Cyclopropanol products 4-8 were obtained in $54-64 \%$ yields. The directing effects by a $\beta$-alkoxide are clearly seen in cyclopropanols 6-8 containing unreacted multi-substituted alkenes. The scope with respect to both substrates - esters and alkenes - is broad, whereas reaction yields are modest due to incomplete conversion. 
Scheme 2

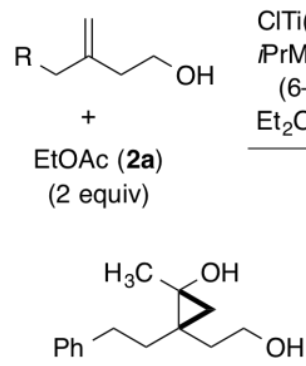

4: $64 \%$<smiles>CC1(O)CC1(CCO)CCO[AsH3-]</smiles>

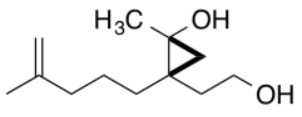

6: $57 \%$

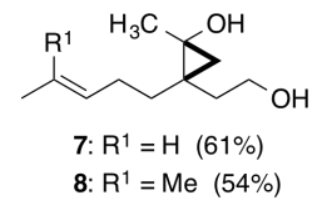

The enantioselective construction of quaternary centers has recently received increasing attention, and a majority of known methods rely on elaboration of chiral tetrasubstituted enolates.12 An attractively functionalized quaternary carbon center is embedded in a 1,2,2-trisubstituted cyclopropanol. Regioselective ring scission of the latter would lead to a convenient generation of a quaternary carbon center placed alpha to a ketone. A conceptually new approach would thus make use of a 1,2,2trisubstituted cyclopropanol as a homoenol equivalent. Toward this end, ketones $\mathbf{1 0}$ and $\mathbf{1 1}$ were prepared by ring opening of $\mathbf{9}$ (3a was protected as the TIPS ether for ease of handling) by

$\dagger$ This article is dedicated to the memory of Professor Harry H. Wasserman (December 1, 1920-December 29, 2013), Yale University, New Haven.

\section{Acknowledgments}

We thank NSF (CHE-1265843) for generous financial support.

\section{References and notes}

1. Kulinkovich, O. G.; Sviridov, S. V.; Vasilevskii, D. A.; Pritytskaya, T. S. Zh. Org. Khim. 1989, 25, 2244.

2. (a) Lee, J.; Kim, H.; Cha, J. K. J. Am. Chem. Soc. 1996, 118 , 4198. (b) Kim, S. H.; Sung, M. J.; Cha, J. K. Org. Synth. 2003 80,111

3. For reviews, see: (a) Kulinkovich, O. G.; de Meijere, A. Chem. Rev. 2000, 100, 2789. (b) Sato, F.; Urabe, H.; Okamoto, S. Chem. Rev. 2000, 100, 2835. (c) Kulinkovich, O. G. Russ. Chem. Bull., Int. Ed. 2004, 53, 1065. (d) Wolan, A.; Six, Y. Tetrahedron 2010, 66, 15. (e) Cha, J. K.; Kulinkovich, O. G. Org. Reactions, 2012, $77,1$.

4. Astashko, D.; Cha, J. K.; Nagavaram, N. R.; Parida, B. B. Eur. J. Org. Chem. 2014, 181 .

5. (a) Savchenko, A. I.; Kulinkovich, O. G. Zh. Org. Khim. 1997, 33, 913. (b) Isakov, V. E.; Kulinkovich, O. G. Synlett 2003, 967.

6. Quan, L. G.; Kim, S.-H.; Lee, J. C.; Cha, J. K. Angew. Chem., Int. Ed. 2002, 41, 2160

7. (a) Bobrov, D.; Kim, K.; Cha, J. K. Tetrahedron Lett. 2008, 49, 4089. (b) Astashko, D.; Lee, H. G.; Bobrov, D. N.; Cha, J. K. J. Org. Chem. 2009, 74, 5528. (c) Joosten, A.; Vasse, J.-L.; Bertus, P.; Szymoniak, J. Synlett 2008, 2455.

8. (a) Kolundzic, F.; Micalizio, G. C. J. Am. Chem. Soc. 2007, 129, 15112. (b) Reichard, H. A.; Micalizio, G. C. Chem. Sci. 2011, 2, 573 and references therein. following the reaction protocols that had recently been developed in our laboratory (Scheme 3). ${ }^{13,14}$

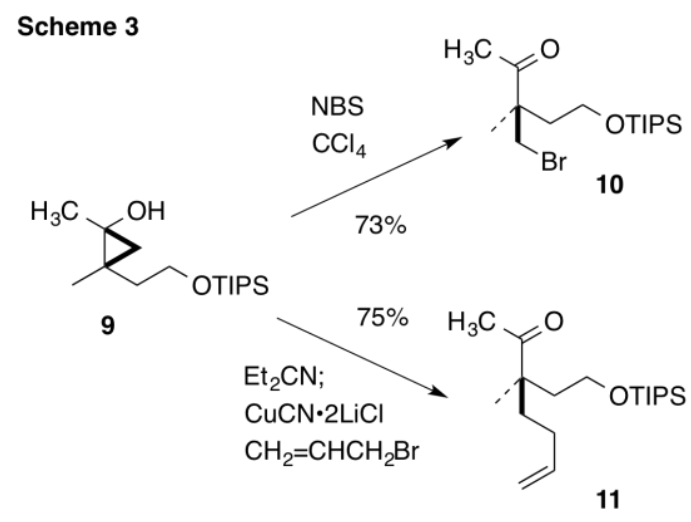

In summary, new access to 1,2,2-trisubstituted cyclopropanols has been devised by utilizing 3,3-disubstituted homoallylic alcohols in the Kulinkovich cyclopropanation of esters. An in situ generated temporary linker overrides unfavorable steric effects to broaden the scope of the Kulinkovich cyclopropanation. Additionally, ring-opening reactions of 1,2,2trisubstituted cyclopropanols are shown to provide a new approach to all-carbon quaternary centers. An enantioselective preparation of 1,2,2-trisubstituted cyclopropanols under the aegis of a resident stereocenter is in progress, as it lends itself to an enantioselective preparation of quaternary carbon centers.

9. (a) Lysenko, I. L.; Kim, K.; Lee, H. G.; Cha, J. K. J. Am. Chem. Soc. 2008, 130, 15997. (b) Lysenko, I. L.; Lee, H. G.; Cha, J. K. Org. Lett. 2009, 11, 3132.

10. There are only a handful methods of preparing trialkyl-substituted cyclopropanols in the literature: 1,2,2-trisubstituted: (a) Toratsu, C.; Fujii, T.; Suzuki, T.; Takai, K. Angew. Chem., Int. Ed. 2000 39, 2725. (b) Nomura, K.; Matsubara, S. Chem. Eur. J. 2010, 16, 703. 1,2,3-trisubstituted: (c) Barluenga, J.; Suero, M. G.; PérezSánchez, I.; Flórez, J. J. Am. Chem. Soc. 2008, 130, 2708.

11. The Simmons-Smith reaction of silyl enol ethers and derivatives offers an alternate route to trialkyl-substituted cyclopropanols. However, stereoselective preparation of trisubstituted silyl enol ether precusors is often problematic.

12. For reviews, see: (a) Corey, E. J.; Guzman-Perez, A. Angew. Chem. Int. Ed. 1998, 37, 388. (b) Denissova, I.; Barriault, L. Tetrahedron 2003, 59, 10105. (c) Christoffers, J.; Baro, A. Eds. In Quaternary Stereocentres, Challenges and Solutions for Organic Synthesis; Wiley-VCH: New York, 2005; pp 336. (d) Douglas, C. J.; Overman, L. E. Proc. Natl. Acad. Sci. USA 2004, 101, 5363. (e) Christoffers, J.; Baro, A. Adv. Synth. Catal. 2005, 347, 1473. (f) Trost, B. M.; Jiang, C. Synthesis 2006, 369. (g) Riant, O.; Hannedouche, J. Org. Biomol. Chem. 2007, 5, 873. (h) Marek, I.; Sklute, G. Chem. Commun. 2007, 1683. (i) Bella, M.; Gasperi, T. Synthesis 2009, 1583. (j) Hawner, C.; Alexakis, A. Chem. Commun. 2010, 46, 7295.

13. Das, P. P.; Belmore, K.; Cha, J. K. Angew. Chem. Int. Ed. 2012, 51, 9517.

14. Parida, B. B.; Das, P. P.; Niocel, M.; Cha, J. K. Org. Lett. 2013, 15,1780 .

\section{Supplementary Material}

Experimental procedures, along with ${ }^{1} \mathrm{H}$ and ${ }^{13} \mathrm{C}$ NMR spectra for cyclopropanol products. 
$\mathrm{R}^{1} \mathrm{OH}_{\mathrm{OH}}$

$+$

$\mathrm{R}^{2} \mathrm{OR}^{\mathrm{O}}$
$\mathrm{CITi}(\mathrm{O}-i-\mathrm{Pr})_{3}$ i-PrMgBr $\mathrm{Et}_{2} \mathrm{O}$, reflux

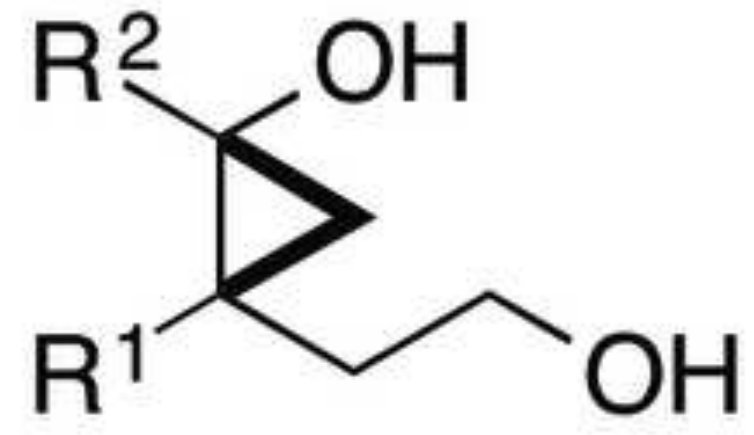

